\title{
LA ETNOHISTORIA, EL SUPLEMENTO Y LA SUPERSTICIÓN*
}

\author{
ETNOHISTORY, THE SUPPLEMENT AND THE SUPERSTITION
}

\author{
André Menard**
}

\begin{abstract}
A partir de una discusión sobre el carácter "suplementario" de la disciplina etnohistórica, en el sentido de que viene a suplir una falta histórica en el conocimiento etnográfico o una falta etnográfica en el conocimiento histórico, se plantea una revisión del problema general de la tensión teórica que ha cruzado históricamente la relación entre acontecimiento o historicidad por un lado y los énfasis culturalistas en la sistematicidad sincrónica de totalidades culturales por otro. Se citan así los actuales postulados antropológicos de una ontología caníbal pero para reformularlos a partir de la necesidad de entender este supuesto "canibalismo" cultural como prueba de la existencia de formas "otras" del archivo y del registro. En este marco se rescata la noción tyloriana de "supervivencia" así como su vínculo con la noción mágicamente connotada de "superstición". De esta forma el artículo propone una perspectiva que permita leer ciertos conflictos actuales en torno a los derechos y demandas indígenas como conflictos entre actores étnicos, administrativos, museográficos o científicos, por el control de espacios u objetos entendibles como una suerte de "supersticiones". Y lejos de limitarse a funcionar como simples objetos, estas "supersticiones" parecen tener una capacidad de agencia acorde con la potencia aurática que emana de su "autenticidad".
\end{abstract}

Palabras clave: Archivos indígenas, canibalismo, supervivencia, patrimonio.

From a discussion on the "supplementary" character of the ethnohistorical discipline- in the sense that it is supposed to fill a historical lack in ethnographic knowledge or an ethographic lack in historical knowledge- I propose a review of the general problem of the relationship between events or historicity in one hand, and the culturalist emphasis on the synchronic and holistic approach to culture, in the other. Then I comment the current anthropological postulates of a cannibal ontology but reformulating them in order to understand this supposed cultural cannibalism as the manifestation of "other" forms of archive and register. Within this framework, I rescue Tylor's notion of "survival" and its link to the magically connoted notion of "superstition". Thus, the paper proposes a perspective for reading current conflicts regarding indigenous rights and demands as conflicts between ethnic, administrative, museological or scientific actors for controlling certain spaces or objects that can be understood as a sort of "superstitions". And far from being mere objects, those "superstitions" seem to have an agency capability according to the auratic power emanating from their "authenticity."

Key words: Indigenous archives, cannibalism, survival, heritage.

\section{Introducción}

En primer lugar me gustaría proponer una reflexión en torno a la categoría de etnohistoria a partir de la noción de suplemento, en la medida en que el mismo término puede ser entendido como un intento disciplinario por dotar a la historia como disciplina y como relato de un suplemento étnico (que en muchos casos ha sido entendido como un suplemento ético) y que puede ser leído en dos sentidos: como el intento por conocer lo que empíricamente ocurrió con las poblaciones étnicas (es decir, no occidentales y carentes de registros alfabéticos, antigua -y quizás aun-inconscientemente considerados pueblos sin historia) en la Historia, o dicho en otras palabras, cómo estos pueblos se inscribieron en la Historia. Y por otro lado como el intento por entender las formas "otras", es decir, culturalmente específicas, en que estos pueblos elaboran algo como una historia, un pasado, una memoria o unos archivos "otros"... Ambos intentos hunden sus raíces en la configuración a partir de inicios del siglo XX, de un o unos paradigmas antropológicos (boasiano, funcionalista, estructuralista...), que en su rechazo de los historicismos especulativos del evolucionismo y del difusionismo, se centraron en una lectura anhistórica de la cultura cuyo énfasis estuvo en relevar la dimensión sincrónica y orgánica de esta última. Se entiende entonces que la etnohistoria haya aparecido en ese contexto como el suplemento que vino a suplir la dimensión que estas perspectivas dejaban de lado (recordemos que

* Resultado Proyecto Fondecyt No 1140921.

** Universidad de Chile, Departamento de Antropología, Chile. Correo electrónico: peromenard@ gmail.com 
cuando Clark Wissler ocupó (quizás) por primera vez el término en 1909, remitía a una propuesta metodológica para suplir el trabajo arqueológico con data documental (Krech 1991: 347), o que en el caso de Jean Vansina en África en los sesenta, se trataba de suplir con material oral la carencia de esta data documental para la reconstrucción de los pasados locales). (Vansina 1985).

De ahí en adelante la etnohistoria se articulará con las distintas estrategias conceptuales mediante las que la razón culturalista ha intentado incorporar la variable del cambio social, del acontecimiento histórico y de las praxis políticas indígenas. No ha sido otra la vocación teórica de términos como los de transculturación y sincretismo (Ortiz 1999 [1940]), o el boom de los estudios sobre movimientos milenaristas de los años sesenta y setenta (Pereira de Queiroz 1968; Worsley 1968; Bastide 1970; Lanternari 1974), o más tarde la referencia a la figura del mestizaje y la hibridación como metáforas de la cultura (Morandé 1984; García Canclini 1990; Amselle 1991). Quizás, uno de los más vistosos esfuerzos contemporáneos en este sentido, sea el del antropólogo brasilero Eduardo Viveiros de Castro con su postulado de las sociedades caníbales (Viveiros de Castro 1997 [1992]). Estas -en las que incluye con más o menos precisión-a las sociedades amazónicas, se caracterizarían por un vacío estructural que las volcaría a la captación literal y figuradamente caníbal del otro en busca de una persistente alteración. Este apetito caníbal del otro puede ser leída como una estrategia caníbal de articulación de una estructura sociocultural con ese otro que sería el acontecimiento. Así, el acontecimiento como marca de historicidad funciona nuevamente como una forma de suplemento, y lo hace con toda la ambigüedad del término, pues este puede ser entendido tanto como la yapa que viene a montarse sobre una totalidad previa, como aquello que suple la carencia estructural de una totalidad incompleta. $\mathrm{Y}$ en esto Viveiros de Castro no se aleja de un modelo estructuralista clásico y su postulado del famoso significante flotante, como condición paradójica de toda totalidad estructural. De esta forma, y pese a su aparente crítica a los postulados durkheimianos de una totalidad social, salva su completitud cultural gracias a un gesto análogo al de este ingenioso artilugio estructuralista. Encontramos una notable aplicación de este modelo teórico para el caso mapuche en el trabajo de Guillaume Boccara en torno a la ontología social reche (ancestros de los mapuche contemporáneos). Según este autor, la calidad caníbal de los reche coloniales estaría demostrada por su ávida y veloz incorporación de elementos españoles, entre los que no duda en señalar los célebres préstamos ganaderos y culinarios: el caballo y el trigo. Pero añade también entre las pruebas de esta actitud caníbal la incorporación de otros elementos como las cautivas o los nombres propios, a los que podríamos añadir vestimentas como los uniformes militares (Boccara 2007 [1998]). El problema de esta demostración reside, según mi punto de vista (Menard 2010), en que se confunden dos tipos de canibalización diferentes: por un lado la canibalización de ciertos recursos y tecnologías que, según se puede constatar en los registros y experiencias etnográficas, fueron tempranamente desprovistos de su carga de alteridad, para confundirse con los elementos vernáculos en el plano de cierta cotidianeidad práctica. Y por otro lado la canibalización explícitamente orientada a la captación de una alteridad y regida por el valor mismo de su heterogeneidad social y por una economía del prestigio. En este último caso, la canibalización funcionaba como una forma consciente y explícita de la alteridad, una suerte de práctica archivística o museográfica indígena, orientada al registro de ciertos gestos de alianza y contagio. El problema puede resumirse como una confusión de distintos tipos de tecnologías: tecnologías bélicas, de transporte, agrícolas, etc., con otras tecnologías orientadas al registro y archivo sobre las que volveremos.

Y lo que subyace a esta confusión es nuevamente el supuesto de un espacio cultural holístico en el que estos diversos elementos y tecnologías vienen a funcionar en forma orgánica, lo que permite considerarlas como ejemplares de una misma totalidad cultural. No es otra la lógica metonímica que suele regir las prácticas museográficas, por las que el artefacto individual expuesto en su vitrina y descrito por la leyenda que lo significa como "cultura X" o "periodo X", funciona como la metonimia de esa totalidad invisible que supone la idea de una cultura o de un periodo X (Clifford 1995 [1988] 262, 273 y ss.). En las páginas que siguen buscaremos proponer una lectura alternativa a estas representaciones culturalistas del objeto y del registro siguiendo la pista que abre la tesis caníbal, pero abriéndola al problema de la singularidad que introduce la noción tyloriana de "supervivencia" así como su vínculo con la noción mágicamente connotada de "superstición". 
De esta forma se propondrá una perspectiva que permita leer ciertos conflictos actuales en torno a los derechos y demandas indígenas como conflictos entre actores étnicos, administrativos, museográficos o científicos, por el control de espacios u objetos entendibles como una suerte de "supersticiones", las que lejos de limitarse a funcionar como simples objetos, parecen tener una capacidad de agencia acorde con la potencia aurática que emana de su "autenticidad".

\section{Archivo, supervivencia y razón patrimonial}

Desde nuestro punto de vista el mérito (involuntario) de la perspectiva caníbal, es que nos permite relativizar el gesto archivístico y museográfico de captación de la alteridad como una práctica de registro compartida por indígenas y modernos, aunque según lógicas políticas y económicas distintas. Resta sin embargo buscar una salida a la ilusión metonímica con que la razón culturalista ha entendido las operaciones de clasificación archivísticas y museográficas, y para ello podemos recurrir a ese primer momento de la antropología en que el estudio de la cultura y la variable histórica no estaban aun disociadas. Pensamos en el momento evolucionista, conscientes de que su recurso a la historicidad adolecía no solo de una, sino que de dos reducciones metonímicas: por un lado la ya conocida de la cultura como totalidad (o etapa cultural), pero sumada a la de la historia como curso evolutivo unívoco, lo que hacía de cada rasgo cultural la marca de un eslabón de esta última. Sin embargo, al leer a Edward B. Tylor constatamos que la cosa no era tan clara y transparente, y que la linealidad histórica podía presentar pliegues y opacidades o síntomas y fantasmas, como diría Didi-Huberman (2002: 59), que constituían de hecho los datos más valiosos para el científico de la cultura. Se trata de las famosas supervivencias, entendidas como aquellas "costumbres carentes de significación (...) que tuvieron un propósito práctico, o al menos ceremonial, cuando y donde surgieron por primera vez, pero que ahora resultan absurdas por haber sido trasplantadas a una nueva fase de la sociedad, en la que el sentido social se ha perdido" (Tylor 1977 [1870]; I: 103), y que de esta forma permitían el trabajo científico de explicar racionalmente aspectos culturales aparentemente irracionales (y que a Didi-Huberman hace hablar de un trabajo sintomatológico que prefiguraba la empresa freudiana). Lo notable es que el mismo Tylor planteaba el concepto de supervivencia como una categoría científica que retomaba el concepto coloquial de "superstición" que de hecho también hace referencia a "fragmentos de una cultura inferior muerta, enclavada en otra superior viva" (Tylor 1977 [1870]; I: 83), y para ello cabe recordar que en su origen etimológico la superstición latina remitía efectivamente a lo que sobrevive, a lo que queda en pie tras la batalla o lo que testifica tras la destrucción y la muerte como los despojos, las reliquias y fantasmas ${ }^{1}$. De esta forma la misma palabra aparecía como una superstición en la medida en que su uso actual "implica un reproche" y por lo tanto obliga a introducir el nuevo término científico "sencillamente para designar el hecho histórico que el vocablo 'superstición' deteriorado, ya no puede expresar ahora" (Tylor 1977 [1870]; I: 83). En otras palabras, el deterioro al que se refiere Tylor, no es otro que el de la carga afectiva, y podríamos añadir mágica o aurática, implicada por la irreductible alteridad histórica -o cultural- que sustrae estos elementos supervivientes de los códigos que determinan usos y prácticas en un espacio y un momento social determinado. Lo importante aquí es que la noción de supervivencia -y la de superstición-, a diferencia de la de suplemento, nos permite por un lado escapar a la determinación orgánica de una totalidad (susceptible de ser representada mediante una lógica metonímica), al relevar en lugar de su carácter estructural, su carácter radicalmente heterogéneo, contingente y fragmentario, y por otro nos permite dar cuenta de aquella dimensión afectiva, aurática, mágica o carismática que están operando los señalados trabajos de registro y archivación de la alteridad en sus versiones tanto modernas y coloniales como indígenas o nativas.

Ahora bien, y pese a que la escuela evolucionista misma puede ser actualmente considerada como una supervivencia o una superstición antropológica, creemos que no deja de tener vigencia en las actuales conformaciones del estatus científico, político y jurídico de los pueblos indígenas a nivel mundial. Esto pues el evolucionismo fue el marco ideológico en que se impuso cierta condición política de estos pueblos que con el desarrollo de los imperios y campañas coloniales del siglo XIX (que tuvieron sus expresiones locales en los procesos de conquista territorial desarrollados por los Estados americanos) pasaron de cierto nivel de horizontalidad política respecto de los Estados europeos, por la que eran 
considerados como enemigos (o potenciales aliados) con los que se guerreaba o pactaba, a uno de asimetría política por la que de enemigos pasaron en el mejor de los casos a objetos de administración poblacional y en el peor al de criminales o de amenaza racial (Schulte-Tenkhoff 1994). Es en este contexto que surge la convicción de la inminente desaparición de los pueblos indígenas o al menos de sus culturas como efecto del inexorable avance de la civilización, vuelta sinónimo de la Historia con mayúscula, adquiriendo el estatus -vigente hasta el día de hoy-de verdaderas supervivencias al interior de un mundo en proceso de modernización y de consolidación de los Estados nacionales. Este proceso puede explicar el que en la reciente Declaración de las Naciones Unidas sobre Derechos de Pueblos Indígenas (ONU 2007), persista la condición de los pueblos indígenas como verdaderas supersticiones de la modernidad, con la carga mágica y afectiva del término, por ejemplo en la referencia que el documento hace a ciertos "derechos espirituales" por los que los pueblos indígenas se distinguirían de otros sujetos de derecho colectivo. Si a esto le sumamos el dato de la autoctonía (como condición de anterioridad al establecimiento de los Estados) así como el de la vulnerabilidad, vemos confirmado el carácter supersticioso -es decir, propio de la supervivencia-de la condición indígena contemporánea² ${ }^{2}$.

En este contexto vemos desplegarse la actual razón patrimonial y su fomento humanista de la diversidad cultural. Todo ocurre como si el mundo vuelto museo evolucionista en el siglo XIX y principios del XX, y su administración colonial de supervivencias culturales ordenadas sobre el plano de una historia universal, hubiera dado paso a un mundo vuelto museo humanista y dedicado a la administración de estas mismas supervivencias, pero sobre el plano perpendicular de una humanidad universal. El mundo entonces como museo y espacio de administración global de aquellos elementos marcados por la primordialidad y la vulnerabilidad, como la naturaleza, la tradición o los mismos pueblos indígenas, que por esta misma lógica pasan a funcionar como los reductos éticos y estéticos de aquello respecto de lo cual la modernidad se afirma negando o destruyendo. Reductos cuyo valor supera -como en el caso de toda superstición-el cálculo utilitario inmediato, ampliando el rango de lo valorizable al plano espiritual de lo intangible. De ahí el actual despliegue gestional de lo patrimonializable -y a fortiori de lo mercantilizable-, por el que vemos desfilar desde los bonos de carbono hasta la tradición oral, pasando por las apelaciones controladas.

Ahora, surge el problema de saber qué ocurre cuando el sujeto de la enunciación es colocado o se coloca en la supersticiosa posición de la supervivencia. Puede manifestarse como "tesoro humano vivo" o informante etnográfico, pero también como emplumado dirigente en los pasillos de la ONU o como reserva ética de la nación desfilando en la parada militar chilena, o recordándonos como en el caso mapuche que se trata de "los primeros chilenos" o de la primera configuración de lo popular (al estilo del Canto General de Pablo Neruda), o como guardianes más o menos new age del medioambiente o de la espiritualidad... Lo importante es que en todos estos casos el actor étnico es desprovisto tanto del poder de interlocución, es decir, de la singularidad del contexto dialógico en que produce su discurso, como de la dimensión política de este último y sobre todo de su historicidad específica. Y con esto no nos referimos solamente al hecho de que en su condición de metonimia de una totalidad cultural se le suele considerar como un actor congelado en la sincronía de un esquema cultural inamovible, es decir, provisto de herencia cultural, pero no de una herencia histórica entendida como capital de acontecimientos inscribibles en el gran archivo de la Historia, es decir, como el recuento lineal de hechos y hazañas, catástrofes y revoluciones, sobre el plano dado, vacío y homogéneo de un tiempo universal (y que corresponde a la primera acepción de la etnohistoria señalada al comienzo). Si no que nos referimos más bien al hecho de que este actor étnico es sobre todo despojado de tecnologías y mecanismos propios de producción de historicidad, esto es de producción de otros tiempos y por lo tanto de historias plurales que -como las supervivenciasafirman las contracorrientes, el fondo de guerras y rumores que despeinan una Historia universal, es decir unívoca y victoriosa, denunciando el reguero de ruinas y cadáveres sobre el que se sostiene. Una historia a contrapelo, en palabras de W. Benjamin, por la que estos mismos actores movilizan la carga supersticiosa, es decir, aurática, no de aquello que simplemente testimonia de un pasado, entendiendo el testimonio como la expresión metonímica de un contenido -en este caso cultural- inmediatamente reproducible, sino que como testificación, es decir, como el montaje infinitamente singular de todo lo que le ha ocurrido, de todo lo que ha producido. Aura 
no representacional, no metonímica de lo auténtico, sino que aura afirmativa, es decir, aura que no emana de aquello que representa (una época bien definida de la Historia o una cultura bien circunscrita de la humanidad), sino de aquello que contiene, implica o complica historias y humanidades heterogéneas y heterocrónicas: "La autenticidad de una cosa es la quintaesencia de todo lo que en ella, a partir de su origen, puede ser transmitido (...), desde su permanencia material hasta su carácter de testimonio histórico" (Benjamin 2003 [1936]: 44).

\section{A modo de conclusión}

La superstición entonces deja de ser un mero error o un mero efecto de la Historia y de su olvido, y por lo tanto dejar de ser el suplemento cultural de una totalidad histórica o el suplemento histórico de una totalidad cultural, y aparece más bien como el impensable punto material de una heterogeneidad en torno al cual y a partir del cual vienen a enunciarse discursos de identidad y de totalidad. De lo anterior se desprende que en lugar de entender el museo o el archivo como efectos del tiempo y sus acontecimientos, es decir, como espacios vacíos y homogéneos de recepción y acopio de acontecimientos vehiculados por un tiempo igualmente vacío y homogéneo, resultan ser el mismo tiempo y la historia unos efectos del archivo. En palabras de Boris Groys "Lo históricamente nuevo, lo actual, lo vivo y lo real no puede diagnosticarse más que en relación a lo 'muerto', lo archivado, lo antiguo. Y esto significa que la función del archivo no puede consistir meramente en retratar o representar la historia, en conservar los recuerdos de la historia tal y como ésta ha tenido lugar en la 'realidad'. Más bien es el archivo el que ofrece la condición previa para que pueda existir en absoluto algo así como la historia, pues solo cuando el archivo está disponible puede llevarse a cabo esa comparación de lo nuevo con lo antiguo que produce la historia como tal" (Groys 2008 [2000]: 14).

Y esto que Groys dice respecto del archivo y del museo modernos, bien podemos aplicarlo a aquellas formas no modernas, a las formas nativas de archivación, como aquellas parcialmente identificadas por las teorías del canibalismo. No es otra por lo tanto la función de cautivos, uniformes y nombres propios, formas salvajes de producción de la superstición y por lo tanto de una historicidad. Recordemos que para Viveiros de Castro, la finalidad última de las guerras de venganza tupí, aquellas por las que el guerrero iba registrando hazañas -es decir, la captura y sacrificio de enemigos- mediante tatuajes y nombres propios, era la producción de un tiempo (Viveiros de Castro 1997: 238), tiempo ya no dado y homogéneo, sino que heterogéneo y producido, pero tiempo al fin y al cabo. De ahí que los eventuales conflictos respecto del destino de cuerpos, prácticas y artefactos disputados por los aparatos de archivación científica y los actores indígenas no debieran tener tanto que ver -y aquí asumo una posición- con una lucha por el reconocimiento identitario, es decir, con una demanda no occidental por entrar en el archivo general de la Historia y de la humanidad general, o dicho en otros términos, por hacer que las culturas singulares se integren al capital de una cultura general (con toda su carga humanista y etnocéntrica), mediante por ejemplo el reconocimiento de su estatus de patrimonio de la humanidad, como por el contrario, con una guerra de archivos, es decir, con la lucha política por la administración de las supersticiones.

Lo vemos por ejemplo en el reclamo persistente por más de un cuarto de siglo de los miembros de la Federación Araucana al Estado chileno, por la restitución de los archivos de esta organización confiscados en 1929 por el gobierno de Ibáñez del Campo (Menard 2013: xiii). Pero lo vemos también en el más pintoresco ejemplo de las actuales demandas por la restitución de cuerpos, como en el caso de las momias atacameñas del Museo de San Pedro de Atacama (Sepúlveda et al. s/f). Creemos que en este caso, y más allá de la referencia explícita a los valores de una ética identitaria, sea esta la de una identidad étnica fundada en el valor universalmente valorable de una espiritualidad codificada en términos de lo sagrado, o en la de una identidad de especie fundada en el valor igualmente universal de una dignidad humana, lo que está finalmente en juego es una lucha por el manejo de esas supersticiones por antonomasia que son los cadáveres. Pues más allá de los postulados de una filiación étnica, postulado muy mediatizado por los discursos antropológicos y arqueológicos que lo han informado, y más allá de los postulados morales respecto de la obscenidad de la manipulación y de la exhibición de unos cuerpos humanos, postulados refutados por las mismas prácticas de exhibición y manipulación vernáculas, lo que subyace es una disputa política y económica por el control de las potencias que esta manipulación y esta exhibición 
tienen por objeto. Pues en tanto superstición por antonomasia, el cadáver, y en especial la momia, cuenta con al menos dos formas de concentración aurática: en primer lugar la potencia aurática de lo inerte, pues como bien dice Augé, para una conciencia viva lo verdaderamente sobrenatural es lo inerte, "piénsese -dice- en la dificultad de concebir un cadáver como algo inerte" (Augé 1998 [1988]: 63), por ello "el poder, corresponde a la inercia bruta, a la pura materialidad" (Augé 1998 [1988]: 31), que como buena supervivencia se carga de carisma por su sustracción al orden de lo cotidiano. $Y$ en segundo lugar, presenta el valor agregado de aquella carga de historicidad materializada que Benjamin identificaba con el aura de lo auténtico, carga que supera el dato metonímico de su origen cultural, y que comprende la totalidad de lo que le ha ocurrido y de lo que ha producido a partir de ella, pues de la Miss Chile (la momia más famosa del Museo de San Pedro) podemos decir lo mismo que Benjamin dice de la Mona Lisa: "Por supuesto que la historia de una pieza de arte incluye más cosas [que las alteraciones de su estructura material y sus sucesivos propietarios]: en la historia de la Mona Lisa, por ejemplo, el tipo y el número de copias que fueron hechas de ella en los siglos XVII, XVIII y XIX" (Benjamin 2003 [1936]: 42).

¿Cómo no ser supersticiosos al constatar sino la vida, al menos la poderosa vitalidad de estas cosas, que en su muerte, hacen pelear a arqueólogos, empresarios, funcionarios e indígenas, me hacen escribir sobre ellas y sus peleas, y de esta forma, se van volviendo cada vez más auténticas, van aumentando su potencial aurático, su magnético capital de historicidad?

\section{Agradecimientos}

El presente artículo se enmarca en el proyecto Fondecyt No 1140921 "Estudio del sentido, uso y circulación de categorías mágico-carismáticas en los discursos antropológicos y políticos referidos al mundo mapuche en Chile entre 1880 y el presente".

\section{Referencias Citadas}

Amselle, Jean-Loup

1991 Logiques métisses. Payot, París.

Augé, Marc

1998 [1988] Dios como objeto. Traducido por A. L. Bixio. Gedisa: Barcelona.

Bárcia, Roque

1882 Primer Diccionario General Etimológico de la Lengua Española. Tomo IV. Álvarez Hermanos, Madrid.

Bastide, Roger

1970 Le prochain et le lointain. Cujas, París.

Benjamin, Walter

2003 [1936] La obra de arte en la época de su reproductibilidad técnica. Traducido por A. E. Weikert. Editorial Itaca, México.

Boccara, Guillaume

2007 [1998] Los Vencedores. Historia del pueblo mapuche en la época colonial. Traducción de Diego Milos. IIAMUniversidad Católica del Norte/ Universidad de Chile. San Pedro Atacama, Santiago.

Clifford, James

1995 [1988] Dilemas de la cultura. Antropología, literatura y arte en la perspectiva posmoderna. Traducción de Carlos Reynoso, Gedisa, Barcelona.

Didi-Huberman

2002 L'image survivante. Histoire de l'art et temps des fantômes selon Aby Warburg. Éditions de Minuit, París.

García Canclini, Néstor

1990 Culturas híbridas. Estrategias para entrar y salir de la modernidad. Grijalbo, México.

Groys, Boris

2008 [2000] Bajo sospecha. Una fenomenología de los medios. Traducido por M. Fontán del Junco y A. Martín Navarro. Pre-Textos, Valencia.
Krech III, Shepard

1991 The State of Ethnohistory. Annual Review of Anthropology 20: 345-375.

Lanternari, Vittorio

1974 Movimenti religiosi di libertà e di salvezza dei popoli oppressi. Feltrinelli, Milán.

Menard, André

2010 Canibalismo, nobilismo y heterogeneidad. Comentario al libro Los vencedores, de Guillaume Boccara. Revista Chilena de Antropología 19: 149-175, 2010, Depto. Antropología Universidad de Chile, Santiago de Chile.

Menard, André

2013 Manuel Aburto Panguilef y los Archivos de la Federación Araucana (estudio preliminar). En Libro Diario del Presidente de la Federación Araucana, Manuel Aburto Panguilef (1940-1951), M. Aburto Panguilef, pp. XICXXIX. CoLibris, Santiago de Chile.

Morandé, Pedro

1984 Cultura y modernización en América Latina. Ediciones Encuentro, Madrid.

Organización de las Naciones Unidas [ONU]

1986 Estudio del problema de la discriminación contra las poblaciones indígenas. Documento ONU E/CN.4/ Sub.2/1986/7, de 1986.

Organización de las Naciones Unidas [ONU]

2007 Declaración de las Naciones Unidas sobre Derechos de Pueblos Indígenas. (marzo 2008) http://www.un.org/esa/ socdev/unpfii/documents/DRIPS_es.pdf (21 enero 2015)

Ortiz, Fernando

1999 [1940] Contrapunteo cubano del tabaco y del azúcar (Advertencia de sus contrastes agrarios, económicos, históricos y sociales, su etnografía y su transculturación). CubaEspaña, Madrid. 
Pereira de Queiroz, Maria Isaura

1968 Réforme et Révolution dans les sociétés traditionnelles. Anthropos, París.

Schulte-Tenckhoff, Isabelle

1994 Traités, parlamentos et le statut des nations amérendiennes. Caravelle 63: 175-191.

Sepúlveda, Tomás, P. Ayala y C. Aguilar s/f. Retiro de Cuerpos Humanos de Exhibición del Museo Arqueológico de San Pedro de Atacama. http://www.dibam.cl/dinamicas/docadjunto_998.pdf (21 de enero de 2015)
Tylor, E. B.

1977 [1870] Cultura Primitiva. Tomo 1. Editorial Ayuso, Madrid.

Vansina, Jan

1985 Oral Tradition as History. University of Wisconsin Press, Madison.

Viveiros de Castro, Eduardo

1997 [1992] A inconstância da alma selvagem e outros ensaios de antropología. Cosac \& Naify, Sao Paulo.

Worsley, Peter

1968 The Trumpet Shall Sound: a Study of "Cargo" Cults in Melanesia. Schocken Books, Nueva York.

\section{Notas}

1 "Llamáronse principalmente supersticiosos los sobrevivientes que honraban en extremo la memoria de los difuntos, ó que daban culto á los retratos de sus parientes, á las imágenes que de ellos sobrevivían ó guardaban en casa (LACTANCIO.)/ Esta es indudablemente la verdadera etimología de la voz del artículo: lo que quedaba de los muertos; hé aquí la significación natural y propia de supérstite, de donde viene SUPERSTICION./ Por consiguiente, la SUPERSTICION era una especie de idolatría con que se daba culto á la memoria, á las reliquias, á los retratos de los difuntos, porque esas prendas se consideraban como una super-existencia, una super-estancia; en fin, una superstición de los antepasados" (Bárcia 1882; IV: 1123).
2 Estos tres elementos aparecen en la definición fundacional que hacía en la década de los ochenta el relator especial José Martínez Cobo: "Son comunidades, pueblos y naciones indígenas, las que teniendo una continuidad histórica con las sociedades anteriores a la invasión y precoloniales que se desarrollaron en sus territorios, se consideran distintos de otros sectores de las sociedades que ahora prevalecen en esos territorios o en partes de ellos. Constituyen ahora sectores no dominantes de la sociedad y tienen la determinación de preservar, desarrollar transmitir a futuras generaciones sus territorios ancestrales y su identidad étnica como base de su existencia continuada como pueblo, de acuerdo con sus propios patrones culturales, sus instituciones sociales y sus sistemas legales" (ONU 1986). 
